\title{
Specifics of the Strategic Management of Innovative Activity of Big Development and Construction Companies
}

\author{
Anatoly Bukreev ${ }^{1}$, Olga Vasilyeva $^{2 *}$, Vyacheslav Vlasenko ${ }^{1}$ and Evgeniya Sizova ${ }^{1}$ \\ ${ }^{1}$ Voronezh State Technical University, 14, Moskovsky prospect, Voronezh, 394026, Russia \\ ${ }^{2}$ Moscow State University of Civil Engineering, 26, Yaroslavskoye shosse, Moscow, 129337, Russia
}

\begin{abstract}
In modern conditions, which are characterized by organizational, economic and institutional transformations, the question about strategic management of innovative activity of big construction and development companies, which are drivers of innovation activity growth, which requires methodical substantiation of the strategy of innovatization of development. Features of innovative activity of large holding companies in these areas are grounded empirically in the article. Problematic field of innovation management is systematized and the advantages of different types of holdings in the implementation of innovations are structured. Authors propose a methodical approach to building of the innovative strategy and innovative construction holding portfolio.
\end{abstract}

\section{Introduction}

Innovative type of economic development involves the diversity and constant renewal of forms of activity, corresponding to shifts in technological basis, value systems, stereotypes of production and consumer behavior in society and business entities, i.e. with any changes in the socio-economic system and its links with the world around. Companies sustain overriding concern in this process, because they determine the dynamics of economic growth, the level of competitiveness of the state and industry, the degree of national security and equal integration unto the world economics.

Radical restructuring of the system of economic management, connected with transition to self-regulation and innovation development is one of the most important directions of reforms in our country. Process of construction operations forms under the influence of the large number of organizational factors. Transformation of control system, improving of it means, first of all, a change in organizational relationships and organizational forms of management, respectively. From these positions, study of the features of the development strategy and formation of the perspective innovation policy of the construction company in the modern Russian economy is urgent research topic, which requires serious scientific approach.

Usage of innovative technologies in the modern economy primarily depend on the effect interrelation between departments, which perform fundamental and applied researches,

* Corresponding author: ol.vasiljevasp@,yandex.ru 
project development, production, and marketing research. In this connection, questions of economy, organization and management of the development of innovative processes, which ensure the efficiency of the companies and, finally, their strategic development, become one of the most urgent.

That's why there appears the necessity of formation of the mechanism of innovationstrategic development of the construction and development companies, which determines priorities for strengthening market positions and methods of their realization. Analysis of the scientific literature on the problems of innovative development of construction and developers' companies [1] leads to the conclusion that the formation of the prospective trend formation is "raw materials-innovation-resource saving", further development of which will allow to overcome the innovative inertia of the industry.

\section{Methods}

Empirical analysis of the problems of innovative development of construction companies is difficult due to the fact that the statistics on innovations in construction is not performed today. That's why assessment of the structure of construction companies by the types of realized innovations is possible on the basis of analysis of the results of the sampling investigation.

Results of the performed among professionals of the construction companies survey [2] showed that of 300 small and medium-sized construction companies of sample, 204 companies realize just production innovations. And from 350 big construction companies, which were surveyed, product innovation is realized by the 169 companies. However, it's possible to unambiguously project results of selective research on a tendency of innovative activities of all companies of general totality only in the case of detection of uniformity of sample with similar sample of the companies on which there are reliable statistical data which shows steady trend. We performed the test of homogeneity of the samples of construction companies and companies of mining and manufacturing industry (for which we have reliable information according to Federal State Statistics Service regarding general totality of the companies) [3].

Performed test, based on the acceptance of the null hypothesis of homogeneity of samples showed the importance of statistics for large companies' $Q=0.556$, which indicates the significance of trends of innovation activities of big companies of mining and manufacturing industry for construction companies and, consequently, the fairness of the findings of sample survey. Confidence limits of sampling investigation of the innovative activity of the big construction companies, calculated on the basis of statistics ( $\mathrm{p}_{\text {lower }}=$ $0.43, \mathrm{p}_{\text {top }}=0.54$ ) indicate that the product innovations realize from $43 \%$ to $54 \%$ of companies with admissible sample error no more than $6 \%$. Consequently, in the structure of innovative activity of the big construction companies nearly half of the total amount falls on product innovations.

More detailed analysis of statistical information about the structure of innovation activity of the companies of mining and manufacturing industry indicates the predominance of small businesses of the product kind of novelties in the innovation structure, and the process innovations in the structure of medium and big companies. Theoretically, such a trend can be explained by the large financial abilities of the big and medium companies. Fairness of this proposition is possible for construction companies with the help of assessment of the homogeneity of samples [4]. Conducted analysis of sample of the big companies showed that percentage of process innovation in them amounts from 39 to $55 \%$.

It should be noted that many big companies (holdings) are no uniform in the projection of advantages at performance of the innovative activity (table 1). 
Table 1. Advantages of different types of holding structures in relation to realization of innovation activity

\begin{tabular}{|l|c|c|c|}
\hline \multicolumn{1}{|c|}{ Advantage of holding structures } & $\begin{array}{c}\text { Vertical } \\
\text { holding }\end{array}$ & $\begin{array}{c}\text { Horizontal } \\
\text { holding }\end{array}$ & $\begin{array}{c}\text { Diversified } \\
\text { holding }\end{array}$ \\
\hline $\begin{array}{l}\text { Possibility of realization of all stages of the } \\
\text { innovative project within single association }\end{array}$ & + & \pm & + \\
\hline $\begin{array}{l}\text { Diversity of implementable innovative projects as a } \\
\text { result of variety of types of activity }\end{array}$ & \pm & - & + \\
\hline $\begin{array}{l}\text { Centralization of management of the innovation } \\
\text { activity and effective management hierarchy }\end{array}$ & + & + & + \\
\hline $\begin{array}{l}\text { Reduction of the costs for scientific researches and } \\
\text { developments at the expense of consolidation of } \\
\text { production, intellectual resources, experience }\end{array}$ & \pm & + & - \\
\hline $\begin{array}{l}\text { Training of innovative personnel, operational } \\
\text { training and retraining }\end{array}$ & + & + & + \\
\hline $\begin{array}{l}\text { Conduction of the single unified account of } \\
\text { innovations of the integrated system of the document } \\
\text { flow, etc. }\end{array}$ & + & + & - \\
\hline $\begin{array}{l}\text { Possibility of selection of new business types as a } \\
\text { result of innovation activity }\end{array}$ & - & - & + \\
\hline $\begin{array}{l}\text { Dispersal of risks of the innovative project between } \\
\text { homogeneous groups of participants }\end{array}$ & + & + & + \\
\hline $\begin{array}{l}\text { Acceleration of the diffusion of innovation within } \\
\text { different fields }\end{array}$ & - & - & + \\
\hline
\end{tabular}

\section{Results}

Results of the conducted analysis testify: usage of form (type) of the product or process innovation will have its place on the most of construction companies, except that, adopted innovations on the small and medium companies, and also independently developed and implemented innovations on the big ones. Assessing innovative capabilities of companies, it should be noted, that for big companies with annual revenue more than 1 bil. USD at other constant conditions probability of technological innovations implementation is more than on $30 \%$ higher than on the companies with annual revenue 100-500 bil. USD. The same is observed in the implementation of organizational innovations, where largest companies have probability of implementation innovative business processes on $46 \%$ higher than probability of companies with annual revenue 100-500 bil. USD under constant conditions [5].

Formation of innovative strategy as concept of interaction between companies with external environment, based on the methodology of advanced realization of technological, organizational, economic changes (which represent portfolio of innovative projects, realizing innovative process) with the purpose of adaptation of the internal environment and formation of market development trends in the form of sustainable competitive advantage, represents complex multistage process. Order of formation of innovative strategy of the OJSC "Russian Railways" holding is shown in the (fig. 1). 


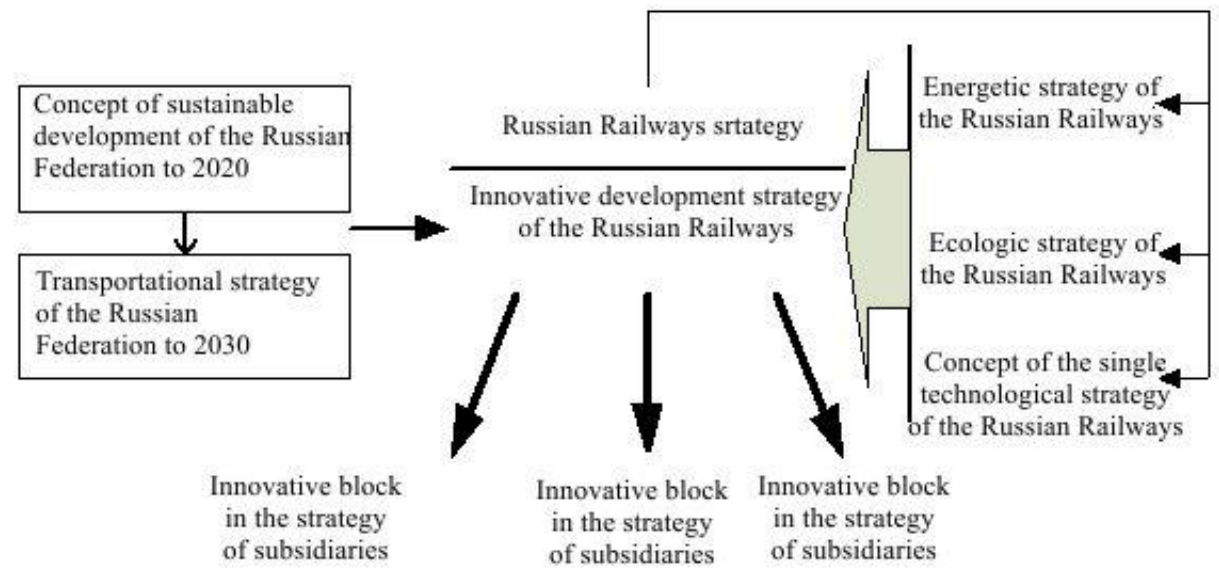

Fig. 1. Order of formation of innovative strategy of the OJSC "Russian Railways" holding

Process of formation of the holding strategy and adjustment of the financial models of target indicators should be presented in the form of the directed graph from mathematical point of view. Targeted strategic indicators of each subsidiary company or branch also form graph, which regards to the functional blocks (fig. 2).

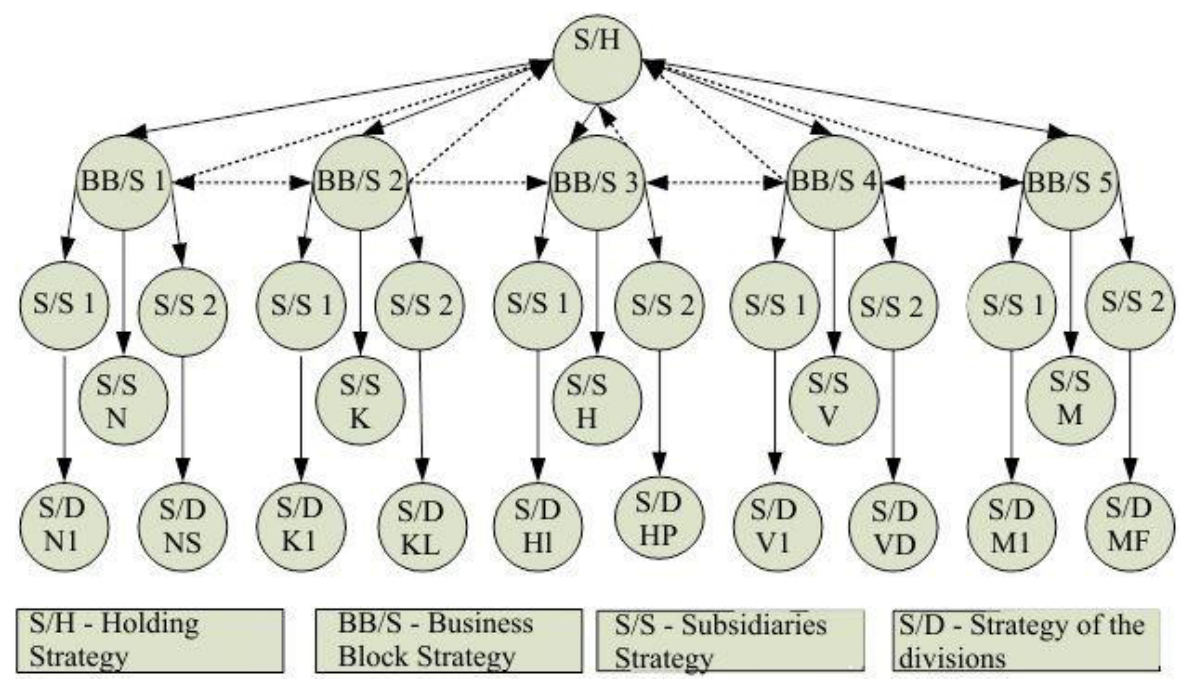

Fig. 2. Directed graph of the building of strategy of the holding (on the example of the OJSC "Russian Railways")

Building of innovative strategy of the big construction holdings is complicated by the necessity of consideration of many factors, which acting for each business unit and subsidiary, which corresponds the multitasking strategy of each unit and necessity of aggregation of the tree of objectives of all business units, with consideration of mission of the holding development. On the assumption of classification of innovations, innovation strategy should integrate the objectives of technical subsystem and policy of the company, management strategy, investment policy, and general mission, purposes and tasks of development under achievement of the stable competitive advantages. So, mechanism and the methodological basis for realization of innovation strategy is innovation process and its component innovative projects [6]. 
In those holdings, where innovation doesn't focus the completely in one subsidiary innovative enterprise, the innovation center performs general management and innovation management, and subsidiary enterprises realize individual innovative programs as set of interconnected successive innovative projects. In this case, all of the innovative programs of the subsidiary enterprises will be the components of the innovative portfolio of the holding structure (fig. 3). Scheme is created without assumptions about the interdependence of innovative projects of various subsidiary enterprises and about possibility of performance of the separate innovative projects by the subsidiary enterprise outside the innovative holding program. However, the algorithm or building of the unique strategy for each business unit and corresponding mission of the holding in general, is identical at every level, similar to the realization of the strategy of big construction company. Innovative process in this context involves task-oriented and organized search for changes which is aimed on the solution of innovative problem situations [7] and in systematic analysis of the potential of these changes as source of social and economic novelties. This process is performed during formation and realization of innovation strategy, particularly in the field of management.

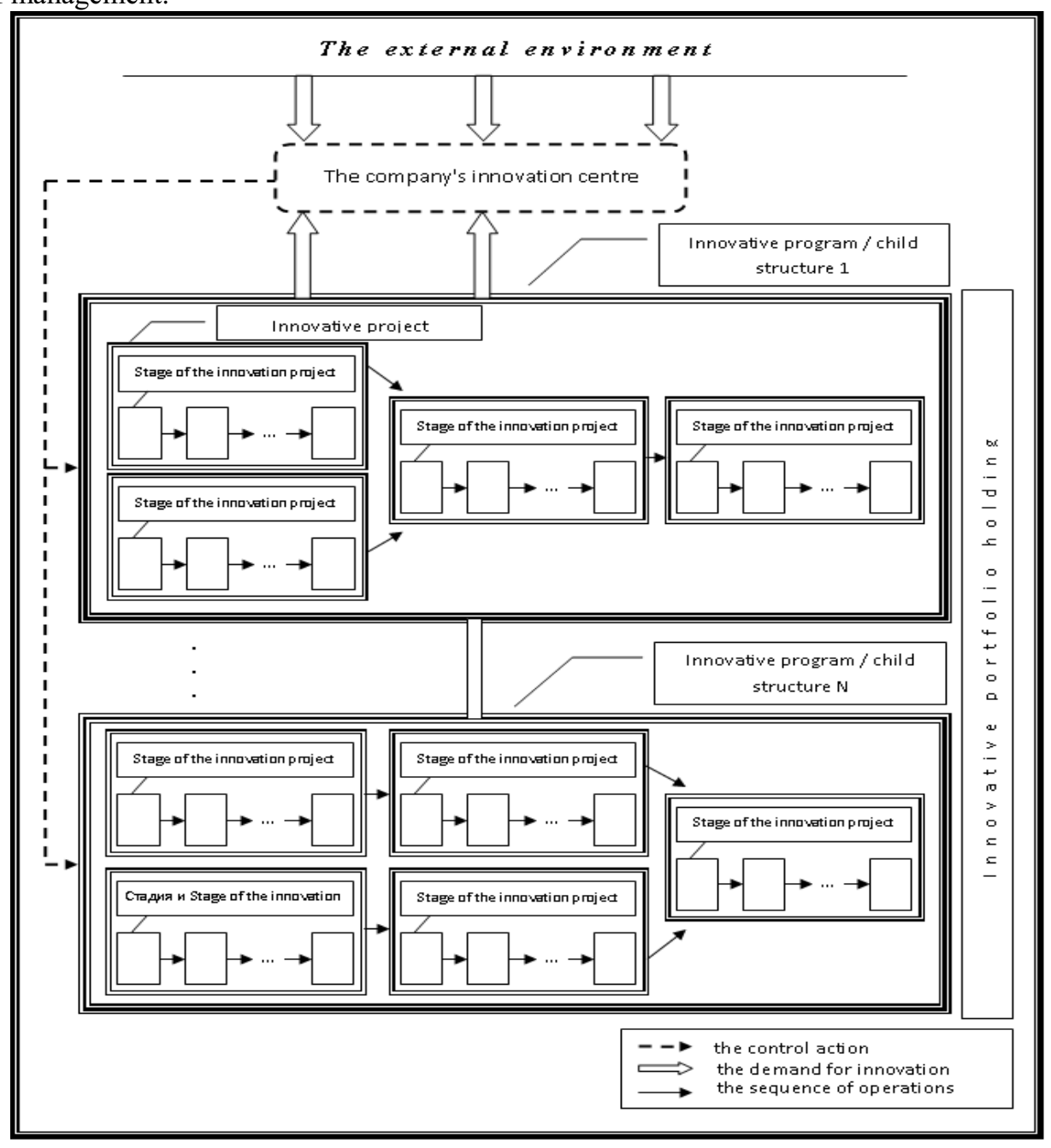

Fig. 3. Decomposition of innovative construction holding portfolio 


\section{Discussion}

Despite the overall high level of innovative potential and innovative activity of the big companies, existing advantages in its realization, scientists and experts [8] distinguish a number of problems in management of innovations, including big (holding) companies at the current stage, such as resistance to innovation of the management of these companies and external investors as a result to reaction on risks of the innovative activity, the problem of reorientation from "improve" to "breakthrough" innovations and overcome of the speed of response and the wish of big companies to consolidate existing positions instead of entrance on the new markets. In addition, the lack of innovative work force, who know the specific of management of the innovative process in complex structures, inefficiency of the system of further training and low level of innovative corporate culture in general as environment, where innovative activity of the holding is performed. In the process of formation of innovative strategy, it's also reacquired to consider the complexity of the reliable prediction of the level of demand for innovative product and coordination problems of innovative subsystem with production, supply, auxiliary and other subsystems [9].

The most important stage in the formation of prospective innovative policy is definition of conditions for the effective management of innovative activity of construction and development company based on the formation of regional «innovation growth points" in construction industry. Mechanism of management by the regional construction complex with its innovative development should form in accordance with the regional zoning policy and innovative development institutes functioning: namely construction must give impetus to the innovative development, combining companies of different fields at functioning of technological clusters and special economic zones, development of infrastructure of the city and region [10].

But, according to our researches, the most effective model of governmental management by the construction complex from the point of view of activation of innovative activity is preservation of co-regulation. So, the necessity of government intervention is kept at introduction of self-regulation for ensuring the legal basis of organizational changes in the industry, creating guarantees of the efficient market development in the conditions of limited competition, protection of the interests of society and entrepreneurs in construction industry $[11,12]$.

In addition to the above prospective of development of technologies and methods, which provide economy of the natural resources, ecological safety of industrial activity, increasing of the level of quality of life of the population, modernization of the production base of the country, growth of the competitiveness of the native companies in conditions of World Trade Organization as effect of the governmental management.

\section{Conclusion}

Today, specific of innovative activity of construction and development companies is determined not only by industrial dimensions, but by the magnitude of activity. On the assumption of capital intensity of innovations and necessity of administrative barriers overcome, including in construction, by the driver of innovative development of the industry will be big companies with optimal, elaborated and coherent innovative strategy, considering the specific of the big companies. Interinfluence of trends of increasing demand for high-quality, energy-efficient and eco-friendly real estate units and the growth of the innovative construction technologies and materials in prospective will also contribute to increasing concentration in construction and development. 


\section{References}

1. Zh. Yu. Kurgaeva, T.V. Halilova. Vestnik kazanskogo tekhnologicheskogo universiteta, 15, 396-402, (2012)

2. O.V. Papel'nyuk, E.I. Sizova. Vestnik Belgorodskogo gosudarstvennogo tekhnicheskogo universiteta im. V.G. Shuhova, 1, 124-127 (2015)

3. S.S. Uvarova, V.S. Kanhva, M.P. Bovsunovskaya, Economika i predprinimatel'stvo, 9, 829-831, (2014)

4. S.S. Uvarova, S.V. Belyaeva, V.S. Kankhva, V.A. Vlasenko. Procedia Engineering, 165, 1317-1322, (2016)

5. A.O. Ul'yanov . Baikal Research Journal, 6, 18, (2015).

6. L. E. Bygballe, M. Ingemansson. Industrial Marketing Management, 43(3), 512-524, (2014)

7. A. Serpell, R. Alvarez . Procedia Engineering, 85, 464-472, (2014)

8. M. Zubizarreta, J. Cuadrado, J. Iradi, H. García, A. Orbe. Evaluation and Program Planning, 61, 22-37, (2017)

9. M. P. Johnson. Journal of Cleaner Production, 142(4), 3769-3781, (2017)

10. X. Liu. Journal of Industrial Organization, 47, 88-120, (2016)

11. S.-V. Rehm, L. Goel, I. Junglas International Journal of Information Management, 36(3), 348-359 (2016)

12. D. I. Prajogo International Journal of Production Economics, 171(2), 241-249 (2016) 